\title{
Acinetobacter junii as an aetiological agent of corneal ulcer
}

\author{
G. Broniek • E. Langwińska-Wośko • \\ J. Szaflik • M. Wróblewska
}

Received: 6 March 2014/ Accepted: 11 June 2014/Published online: 24 July 2014

(C) The Author(s) 2014. This article is published with open access at Springerlink.com

\begin{abstract}
Rods of the Acinetobacter genus are present mainly in the external environment (e.g. water, soil) and in animals, while in humans they may comprise physiological flora. The main pathogenic species is Acinetobacter baumannii complex, which constitutes a common cause of nosocomial infections, particularly in patients with underlying diseases and risk factors (e.g. prior broad-spectrum antibiotic therapy, malignancy, central venous catheter, mechanical ventilation); however, infections of the eye caused by strains of Acinetobacter spp. are very rare. We report a unique case of community-acquired corneal ulcer caused by Acinetobacter non-baumannii (possibly A. junii), in a patient with no risk factors identified. The case highlights the need for obtaining a sample from the cornea for bacteriological culture in the case of suspected ophthalmic infection as identification of the pathogen, and assessment of its susceptibility profile enables proper antibiotic therapy, improves the outcome and may constitute an eyesightsaving management.
\end{abstract}

Keywords Corneal ulcer - Ulcerative keratitis . Acinetobacter junii - Healthcare-associated infections . Community-acquired infections

G. Broniek · E. Langwińska-Wośko · J. Szaflik ·

M. Wróblewska ( $\square)$

Clinical Ophthalmological Hospital, Medical University of

Warsaw, Warsaw, Poland

e-mail: marta.wroblewska@wum.edu.pl

E. Langwińska-Wośko · J. Szaflik

Chair and Department of Ophthalmology, IInd Faculty of

Medicine, Medical University of Warsaw, Warsaw, Poland

\section{Introduction}

Rods of the Acinetobacter genus are Gram-negative coccobacilli. They are present mainly in the external environment (e.g. water, soil) and in animals, while in humans they may comprise physiological flora, particularly in hot and humid climate countries [1]. The main pathogenic species is Acinetobacter baumannii complex, which constitutes a common cause of nosocomial infections, particularly in patients with underlying diseases and risk factors (e.g. prior broad-spectrum antibiotic therapy, malignancy, central venous catheter, mechanical ventilation) $[1,2]$. However, infections of the eye caused by strains of Acinetobacter spp. are uncommon. We present a unique case of community-acquired Acinetobacter non-baumannii (possibly A. junii) corneal ulcer in a patient without recognised risk factors.

\section{Case report}

We report a community-acquired corneal ulcer caused by A. junii in a 51-year-old woman with no significant past medical history. She was admitted to the E.R. with a diagnosis of corneal ulcer (ulcerative keratitis) and anterior uveitis of the right eye. For the previous 2 days she complained of flu-like symptoms and pain of the affected eyeball. She was generally in good health, with no history of ophthalmological diseases or treatment. Eight years earlier she was diagnosed with unexplained anaemia, but results of the recent blood tests were within the normal range.

On examination the eyelid and conjunctiva were swollen, with deep and superficial conjunctival injection. There was a large (1/2 of the corneal diameter), white and deep 
inflammatory infiltrate. A 2-mm hypopyon (accumulation of pus in the anterior chamber) was noticed. Best corrected visual acuity (BCVA) was 0.2 .

Corneal scrapings were taken at presentation for microbiological examination. A strain of A. junii was isolated in pure culture and identified susceptible to all tested antimicrobials: aminoglycosides (amikacin, gentamicin, tobramycin, neomycin), tetracycline, chloramphenicol, norfloxacin and sulphonamides. The species identification and susceptibility testing was performed in a clinical microbiology laboratory using an automated system VITEK $^{\circledR} 2$ Compact (bioMerieux). It should be noted, however, that according to the present data the identification of A. junii by this automated system is uncertain, in contrast to A. baumannii complex [3].

Empiric antibiotic therapy was started on admission and comprised systemic ciprofloxacin $(0.2 \mathrm{~g}$ b.d.) and topical chloramphenicol ointment (q.i.d.). After obtaining the culture result and an antibiogram of the isolate, this treatment was continued as the strain was susceptible to the antibiotics used in empiric therapy. In the meantime (whilst awaiting the culture results) there was a clinical improvement of the condition of the patient's eye.

Four days later the corneal ulcer continued to diminish in size and depth, with gradual epithelisation noted in the periphery of the affected area. Descemet's membrane folds decreased substantially and hypopyon virtually resolved, while fine dust-like deposits were detected on the corneal endothelium. The infection resolved within 2 weeks, with only slight opacity, thinning and single pigment granules still present in the lower nasal quadrant of the cornea. The patient was discharged with BCVA 0.7.

\section{Discussion}

Acinetobacter species are opportunistic pathogens causing nosocomial infections [2]. Relatively few infections caused by Acinetobacter spp. are community acquired, reported primarily from countries with tropical or subtropical climate, and mainly affected patients with some form of comorbidity or associated with heavy smoking and excess alcohol consumption [4, 5]. Clinical forms of Acinetobacter infections include mainly the respiratory tract, bloodstream infections, peritoneum, urinary tract infection, surgical wounds, meningitis, skin and soft tissue infections, while eye infections are rare [2].

The spectrum of ocular infections caused by Acinetobacter spp. comprises acute or chronic conjunctivitis, corneal ulcers and dacryocystitis [6,7]. Exposure of cornea, use of contact lens, penetrating keratoplasty, and immunosuppression have been implicated as predisposing factors to eye infections by Acinetobacter [6]. Rods of the genus Acinetobacter have been implicated in the aetiology of endophthalmitis and preseptal cellulitis usually preceded by bacteraemia [4, 8-10]. Keratitis caused by Acinetobacter spp. is rare and may result from trauma, contact lens wear or ocular surgery, e.g. penetrating keratoplasty-PKP or cataract surgery $[4,6,8,11-13]$. In a study reporting 750 cases of postoperative ocular infections, Acinetobacter spp. comprised $2 \%$ of strains cultured from clinical specimens, being second most common pathogen (after Pseudomonas) among Gram-negative bacteria [14]. Interestingly ocular colonisation with Acinetobacter may precede its appearance in sputum or blood cultures 1-2 days later [15]. Acinetobacter keratitis has also been reported in a patient with chronic lymphocytic leukaemia [16].

Ocular surface colonisation by Acinetobacter spp. may be particularly important in sedated intensive care unit patients [17]. Incomplete lid closure leads to drying of the conjunctiva and the corneal epithelium, resulting in lesions ranging from punctate epithelial erosions to a deep ulcer formation [17].

In some cases infections caused by Acinetobacter spp. are endogenous, without any obvious predisposing factors $[4,9]$. Clinically these ocular infections take a form of endophthalmitis or keratitis with or without ulcer formation $[9,11,13]$. Recently a case of $A$. baumannii endophthalmitis has been reported, which resulted from intravitreal ranibizumab injection [18]. Eye infections may be caused by $A$. baumannii as well as other species such as $A$. anitratus or A. lwoffii $[4,8,11]$. Newly described Acinetobacter species, e.g. A. gyllenbergii-like isolate, have been implicated in ocular infections as well [7].

Acinetobacter junii rarely causes infections in humans [19]. In larger analyses from Europe, strains of A. junii constitute $3.6-4.8 \%$ of all Acinetobacter spp. isolates$12 / 331$ and $9 / 186$, respectively [20,21]. It mainly affects patients who have had prior antimicrobial therapy, invasive procedures, or malignancy [19]. Out of 34 patients with $A$. junii infections $80 \%$ were hospital-acquired; four patients died $(11.4 \%)$ despite adequate antibiotic therapy in three cases [19]. Only one patient had ocular involvementkeratitis. Acinetobacter junii has been associated mainly with bacteremia and sepsis in neonates and paediatric oncologic patients [22]. Linde et al. described a case of catheter-related bloodstream infection caused by $A$. junii in an adult oncologic patient [22].

Henao-Martinez et al. [23] described a case of community-onset non-traumatic cellulitis caused by a strain identified as A. junii-johnsonii. Corneal perforation due to $A$. junii has been reported very rarely $[5,24]$.

In conclusion it should be noted that $A$. non-baumannii species, including $A$. junii, may cause a communityacquired corneal ulceration in an otherwise healthy patient. Ophthalmologists should obtain a sample from the cornea 
for bacteriological culture in the case of suspected infection as identification of the unique causative pathogen, and its susceptibility profile enables administration of proper antibiotic therapy, improves the outcome and may constitute an eyesight-saving management.

Conflict of interest On behalf of all authors, the corresponding author states that there is no conflict of interest.

Open Access This article is distributed under the terms of the Creative Commons Attribution License which permits any use, distribution, and reproduction in any medium, provided the original author(s) and the source are credited.

\section{References}

1. Antunes LCS, Visca P, Towner KJ. Acinetobacter baumannii: evolution of a global pathogen. Pathog Dis. 2014;0:1-10 (published online: 27.01.2014).

2. Bergogne-Berezin E, Towner KJ. Acinetobacter spp. as nosocomial pathogens: microbiological, clinical, and epidemiological features. Clin Microbiol Rev. 1996;9:148-65.

3. Schulte A, Seifert H. Evaluation of VITEK 2 for identification of Acinetobacter species. \#P1682, ECCMID 2012, London. http:// registration.akm.ch/einsicht.php?XNABSTRACT_ID $=143582 \& X$ NSPRACHE_ID $=2 \&$ XNKONGRESS_ID $=161 \&$ XNMASKEN_ ID $=900$.

4. Chen K-J, Hou C-H, Sun M-H, Lai C-C, Sun C-C, Hsiao C-H. Endophthalmitis caused by Acinetobacter baumannii: report of two cases. J Clin Microbiol. 2008;46:1148-50.

5. Prashanth K, Ranga MP, Rao VA, Kanungo R. Corneal perforation due to Acinetobacter junii: a case report. Diagn Microbiol Infect Dis. 2000;37:215-7.

6. Marcovich A, Levartovsky S. Acinetobacter exposure keratitis. Br J Ophthalmol. 1994;78:489-90.

7. Pluquet E, Bremond-Gignac D, Milazzo S, Mammeri H. Unusual acute endophthalmitis due to an as yet unclassified Acinetobacter gyllenbergii-like isolate. J Med Microbiol. 2011;60:1379-82.

8. Crawford PM Jr, Conway MD, Peyman GA. Trauma-induced Acinetobacter lwoffi endophthalmitis with multi-organism recurrence: strategies with intravitreal treatment. Eye (Lond). 1997;11:863-4.

9. Gopal L, Ramaswamy AA, Madhavan HN, Battu RR, Sharma T, Shanmugam MP, Bhende M, Ratra D, Shetty NS, Rao MK. Endophthalmitis caused by Acinetobacter calcoaceticus: a profile. Indian J Ophthalmol. 2003;51:335-40.
10. Miller J. Acinetobacter as a causative agent in preseptal cellulitis. Optometry. 2005;76:176-80.

11. Melki TS, Sramek SJ. Trauma-induced Acinetobacter lwoffi endophthalmitis. Am J Ophthalmol. 1992;113(5):598-9.

12. Corrigan KM, Harmis NY, Willcox MD. Association of Acinetobacter species with contact lens-induced adverse responses. Cornea. 2001;20(5):463-6.

13. Zabel RW, Winegarden T, Holland EJ, Doughman DJ. Acinetobacter corneal ulcer after penetrating keratoplasty. Am J Ophthalmol. 1989;107(6):677-8.

14. Mahajan VM. Postoperative ocular infections: an analysis of laboratory data on 750 cases. Ann Ophthalmol. 1984;16(9):847-8.

15. Oishi M, Miyao M, Ozaki K. Clinical studies of ocular infections from which Acinetobacter calcoaceticus was isolated. Jap J Clin Ophthalmol. 2001;55:887-90.

16. Presley GD, Hale LM. Corneal ulcer due to Bacterium anitratum. Am J Ophthalmol. 1968;65:571-2.

17. Mela EK, Drimtzias EG, Christofidou MK, Filos KS, Anastassiou ED, Gartaganis SP. Ocular surface bacterial colonisation in sedated intensive care unit patients. Anaesth Intens Care. 2010;38:190-3.

18. Cankaya C, Cumurcu T, Doganay S. Acinetobacter baumannii endophthalmitis following intravitreal ranibizumab injection. Ret-Vit. 2013;21:59-62.

19. Hung YT, Lee YT, Huang LJ, Chen TL, Yu KW, Fung CP, Cho WL, Liu CY. Clinical characteristics of patients with Acinetobacter junii infection. J Microbiol Immunol Infect. 2009;42:47-53.

20. van den Broek PJ, van der Reijden TJK, van Strijen E, HelmigSchurter AV, Bernards AT, Dijkshoorn L. Endemic and epidemic Acinetobacter species in a university hospital: an 8-year survey. J Clin Microbiol. 2009;47:3593-9.

21. Seifert H, Dijkshoorn L, Gerner-Smidt P, Pelzer N, Tjernberg I, Vaneechoutte M. Distribution of Acinetobacter species on human skin: comparison of phenotypic and genotypic identification methods. J Clin Microbiol. 1997;35:2819-25.

22. Linde HJ, Hahn J, Holler E, Reischl U, Lehn N. Septicemia due to Acinetobacter junii. J Clin Microbiol. 2002;40:2696-7.

23. Henao-Martínez AF, González-Fontal GR, Johnson S. A case of community-acquired Acinetobacter junii-johnsonii cellulitis. Biomedica. 2012;32:179-81.

24. Wand M, Olive GM Jr, Mangiaracine AB. Corneal perforation and iris prolapse due to Mima polymorpha. Arch Ophthalmol. 1975;93:239-41. 